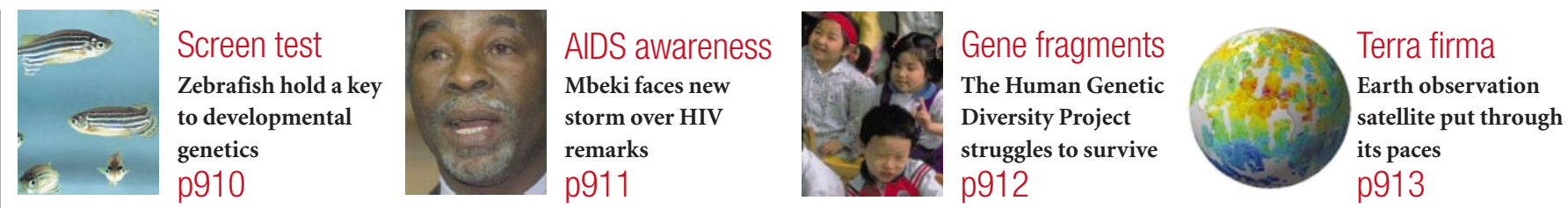

\title{
Budget crisis forces hard choices on US high-energy physics
}

Washington

US high-energy physicists, facing deep budget cuts and divided on their priorities, have been given six months to come up with a consensus on the future direction of their $\$ 700$ million research programme.

Peter Rosen, head of the high energy and nuclear physics office at the Department of Energy, asked the department's High Energy Physics Advisory Panel (HEPAP) last month to revisit a report that it produced in 1998 on the future direction of the discipline in the United States.

Rosen believes the new study is needed by this autumn to shore up support for the high-energy physics programme in Washington. Officials in both Congress and the Clinton administration have expressed concern about the what they perceive as a lack of clarity about the programme's goals.

"There's a lot of questions about whether the community really deserves the funding which it asks for," says Michael Lubell, head of public affairs at the American Physical Society in Washington. Lubell says that the field badly needs to make more of the spinoffs from particle physics — such as the invention of the worldwide web and several medical technologies — instead of relying on the brilliance of its research to make the case for funds.

Many observers say that since the collapse of the Superconducting Super Collider project in Texas in 1993, high-energy physics has struggled to regain prestige in Washington.

Areas of physics that were once far less fashionable have won more support solid-state physics, for example, will benefit from President Clinton's recent nanotechnology initiative. But the budget for highenergy physics has been frozen for several years, causing substantial staff reductions at the two largest particle-physics laboratories, Stanford Linear Accelerator Center (SLAC) in California and Fermilab in Illinois.

A meeting of HEPAP at Fermilab last month was told that the two laboratories are facing a $\$ 50$ million shortfall in the next financial year, under the Department of Energy's budget plan. Last summer, the laboratories - aided by the fact that Fermilab is

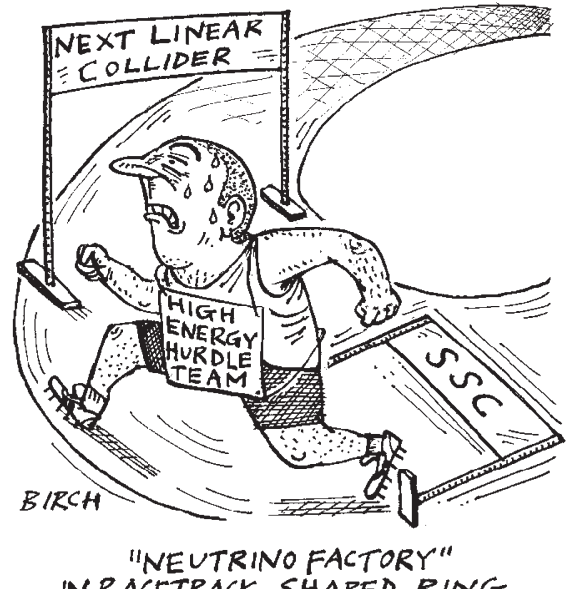

INRACETRACK SHAPED RING..

in the district of Dennis Hastert (Republican, Illinois), the speaker of the House of Representatives - persuaded Congress to add some $\$ 18$ million to the budget proposed for them by the administration.

Leaders of the programme are hoping, meanwhile, that the study requested by Rosen will help to provide direction for the field. "It will be a unifying process for the community," predicts Jonathan Dorfan, director of SLAC.

The 1998 study said that the top priority was to operate existing facilities at SLAC and Fermilab. It added that research and development work should continue on a proposed electron-positron collider, the Next Linear Collider (NLC), in order to complete a conceptual design for it, and that extended research programmes should investigate two other machines, a muon collider and a very large hadron collider.

Some sources in the high-energy physics community say that Rosen wants the new study to sharpen the focus of this agenda by calling explicitly for the construction of the NLC. But not everyone has rallied behind the NLC. Some physicists believe that, at an estimated cost of about $\$ 5$ billion, it is too expensive to be built in the United States in the foreseeable future, and that the community should be exploring other options instead.

"The high-energy physics programme will go the way of the fusion programme if it pursues the NLC as its best bet," warns John Peoples, former director of Fermilab. The

\section{UK science spend 'not sensible'}

\section{London}

Increases in the British government's spending on fundamental science are being funded by cuts to research in more directly applicable areas, a cross-party group of members of parliament (MPs) warned this week. They said that "a policy of robbing Peter to pay Paul is neither sensible nor sustainable".

A report from the House of Commons select committee on science and technology points out that civil departments, such as the Ministry of Agriculture, Fisheries and Food (MAFF) and the Department of Health, have suffered a long-term decline in support for their research spending. This is in spite of their role of informing government policy, addressing gaps in the science base and responding to short-term research needs.
The committee says that although public confidence in agriculture is at an all-time low and the farming industry is in crisis, MAFF's research and development budget has been cut by ten per cent in the past three years.

The committee says this decline should be halted or reversed. It also recommends that the minister for science be elevated to Cabinet level. At present science is represented within the Cabinet by the Secretary of State for Trade and Industry, Stephen Byers.

The lobby group Save British Science wants a Ministry of Science - something the cross-party group of MPs does not agree with. But Peter Cotgreave, director of Save British Science, said elevating the position of the science minister would be "a decent compromise".

Natasha Loder 


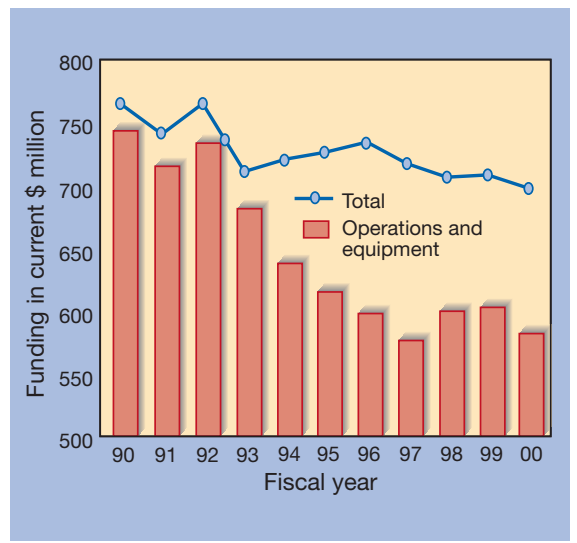

Fading funds: US financial backing for highenergy physics has slowed down significantly.

fusion research programme in the United States lost one-third of its budget in 1995 after Congress decided that US involvement in the International Thermonuclear Experimental Reactor was too expensive to pursue.

Since the 1998 study, physicists at Fermilab and elsewhere have been developing the case for a 'neutrino factory', which would generate an intense beam of neutrinos from the decay of muons circulating in a racetrack-shaped ring.

Such an experiment, which would cost about a billion dollars, could build on current efforts in Japan, the United States and Europe to detect neutrino oscillation, and therefore measure the mass of the neutrino. Some advocates of the neutrino factory see it as a realistically priced, intermediate step towards a muon collider that could eventually be built at Fermilab.

"There are a lot of people worrying about their own survival, and they are not prepared to take the NLC on as a major thrust," says Lubell. One laboratory official goes further, saying that the current budget crunch "has created a crisis mode of thinking, close to a feeling of panic" in the field which, the official adds, is not conducive to reaching a consensus on future projects.

"It's a very difficult situation," says Nick Samios, former director of the Brookhaven National Laboratory. "Our credibility is not high, because of the Superconducting Super Collider debacle." Samios supports the NLC construction, but notes that current plans for a collider with an initial energy of 500 $\mathrm{GeV}$, upgradable to $1 \mathrm{TeV}$, falls well short of a previous assumption by US physicists that such a machine should aim for an energy of $1.5 \mathrm{TeV}$.

Whatever its eventual specification and site, US physicists are in agreement that the NLC will have to be a truly international project. The $\$ 20$ million annual research programme into the NLC, which is centred at SLAC, has been closely coordinated with a similar programme at the High Energy Accelerator Research Organization (KEK) in Japan.

At a meeting in London earlier this month, the global science forum of the Parisbased Organization for Economic Cooperation and Development discussed the formation of a high-energy physics workshop that could provide the necessary framework for the international construction of machines such as the NLC.

Colin Macilwain

\section{'Saturation screen' lets zebrafish show their stripes}

\section{London}

Over the next year, a mammoth project involving some 17 million tropical fish is expected to yield a treasure trove of data for researchers working on the genetics of vertebrate development.

Artemis Pharmaceuticals, a company based in Cologne, announced last week that it has joined forces with Christiane Nüsslein-Volhard of the Max Planck Institute for Developmental Biology in Tübingen to conduct a zebrafish 'saturation mutagenesis screen'.

The project, dubbed the Tübingen 2000 Screen, is already under way, and will cost around US\$10 million. Its goal is to apply chemical mutagens to zebrafish sperm to introduce point mutations randomly throughout the genome.

Researchers will breed fish using the treated sperm, and screen for those that show developmental abnormalities. From these animals, geneticists can then try to clone the mutated gene. Applying this technique on a sufficiently large scale should make it possible to mutate every important developmental gene - hence the term 'saturation' mutagenesis.

Nüsslein-Volhard shared a Nobel prize in 1995 for her work in developing saturation mutagenesis in the fruitfly Drosophila. By this time, she had also begun to apply the technique to the zebrafish (Danio rerio) to investigate the function of genes that control the development of vertebrates. This popular aquarium fish is ideal for developmental studies, as its embryos are transparent, making it easy to spot abnormalities in internal structures.

Nüsslein-Volhard's previous zebrafish screen produced more than 1,000 mutants. A parallel screen - conducted by a team led by Wolfgang Driever, now at the University of Freiburg — produced half as many mutants again. Mutants from both screens were described in a special issue of the journal Development (see Nature 384, 514; 1996). "A lot of interesting mutants were found, and it has been possible to start to characterize some of those molecularly," says Phil Ingham, a developmental biologist at the University of Sheffield.

But the original screens failed to mutate every important zebrafish developmental gene. "We probably didn't get to saturation," says Nüsslein-Volhard, who is a co-founder of Artemis. In addition, some interesting mutants may have been overlooked because researchers didn't spot subtle developmental abnormalities in every single organ and physiological system.

This time, researchers with different expertise will examine the same fish to ensure that fewer mutants get overlooked. The screen will be twice the scale of Nüsslein-Volhard's previous project. Peter Stadler, chief executive officer of Artemis, says the project will employ about 50 people.

Scientists at Artemis will mainly screen for abnormalities giving information on gene function that could provide leads for drug development. These include

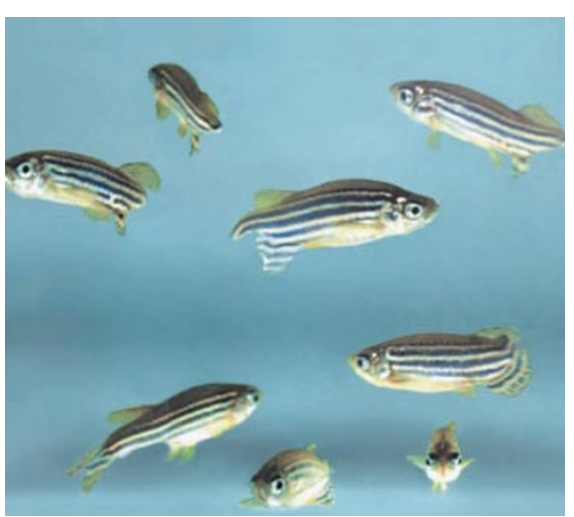

Variety shoal: zebrafish with the mini fin gene, one of a host of mutants known in the species.

abnormalities in the production of cartilage and bone, and in the cardiovascular system.

Nüsslein-Volhard's team, together with researchers from elsewhere in Germany, Britain and the United States, will look for mutants yielding fundamental insights into the processes of development. These will include fish with abnormalities in the formation of the eyes and the neural crest paired strips of cells that form early in development, which give rise to a variety of tissues including the central nervous system.

Artemis will have six weeks to patent any discoveries. After this period, results will be made available to other scientists in the normal way, says Stadler. Peter Aldhous - http://www.artemis-pharmaceuticals.de/ html/topic2000.html

http://www.eb.tuebingen.mpg.de/abt.3/home_text.htm 